\title{
The Acquisition of Topological Relations in Indonesian*
}

\author{
I Nyoman Aryawibawa \\ Universitas Udayana, Denpasar, Indonesia
}

\begin{abstract}
Many scholars have proposed concepts relevant to topological relations, e.g., Herskovits (1982), Levinson, Meira, and The Language and Cognition Group (2003). The objectives of the author's experimental investigation of Indonesian topological relations are to examine what concepts relevant to the relations and to point out factors affecting the acquisition of them. The author's experiment used scaling tasks for adult participants, and production and comprehension tasks for children participants. The results showed that the concept expectedness governs the use of Indonesian topological relations. The author further argues that both conceptual and linguistic concepts affect the acquisition of topological relations in Indonesian.
\end{abstract}

Keywords: topological relation, linguistic concept, conceptual concept, acquisition

\section{Introduction}

Many scholars have investigated the pattern of acquisition of topological relations. Piaget and Inhelder (as cited in Johnston, 1985, p. 969) explain that at the earliest stage, the spatial notions acquired by children are those related to the functions of an object, e.g., containment, support. Carlson-Radvansky, Covey, and Lattanzi (1999) also conducted two different experiments to investigate how the function of objects influences the use of spatial terms, e.g., above and below. The results showed that there was a significant interaction between functional relatedness and alignment. Levinson, Meira, and The Language and Cognition Group (2003), however, pointed out that the concept attachment was important in nine unrelated languages they studied.

In this study, the author is attempting to examine two hypotheses. First, the expectedness of relations between objects in topological relations affects the acquisition of topological prepositions in Indonesian. Second, the conceptual and linguistic factors play a role in the acquisition.

\section{Method}

To examine the role of the expectedness of spatial relations between objects in the acquisition of topological prepositions in Indonesian, the author used three different tasks, i.e., a scaling task, a production task, and a comprehension task, that will be discussed in the following sections.

\section{Scaling Tasks}

Participants. Before the stimuli were tested with the young subjects, control stimuli were tested with four adult speakers of Indonesian. They were undergraduate students at Faculty of Letters, Universitas Udayana in

\footnotetext{
* This study was partly funded by the Institute of International Education. The shorter Indonesian version of the paper has been published in the proceeding of Kongres Antarabangsa Bahasa dan Budaya, Brunei Darussalam, 2011.

I Nyoman Aryawibawa, Ph.D. at English Department, Faculty of Arts, Universitas Udayana.
} 
Bali ( $M=19 ; 2$ years old). They voluntarily participated in this experiment.

Stimuli. The control stimuli were 18 color photographs $(10.2 \times 5.3 \mathrm{~cm})$ showing the two kinds of spatial relations, i.e., the expected and unexpected relations, the same as those used in the stimuli for the young subjects. The concepts containment, support, and attachment were also represented by the pictures. The photographs were randomly arranged. The main objective of testing the control stimuli was to examine the adults' responses to the expectedness of spatial relations shown in the photographs.

Procedure. The adult participants were presented all the photographs with two Indonesian sentences below each photograph. The sentences described the spatial relations in the pictures using prepositions indicating the expected relation, i.e., di ("expect”), and the unexpected relation, i.e., di dalam ("expect inside”), di atas ("expect up"). They were asked to scale the sentences. The scale ranged from 1 to 4 ( 1 = the least appropriate, 2 = less appropriate, 3 = appropriate, 4 = the most appropriate). The subjects were encouraged to use all the scale. The subjects were naïve about the hypotheses. One example of stimuli is presented in Figure 1. The complete list of stimuli can be found in Aryawibawa (2010).

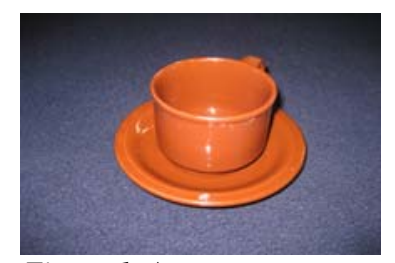

Figure 1. A cup on a saucer.

Note. Cangkir di alas cangkir "The cup is on the saucer"; Cangkir di atas alas cangkir "The cup is on the saucer".

Before the actual experiment, the author did practice trials (two extra stimuli for each subject). The question (in Indonesian) the author asked to each participant before scaling the pictures is as follows: Apakah pemakaian preposisi dalam kalimat-kalimat di samping gambar ini tepat penggunaanya untuk menggambarkan letak benda dalam gambar tersebut? ("Are the use of prepositions in the sentences appropriate to describe the topological relation in the picture?”). Then, the participant had to scale the use of prepositions in the sentences describing the spatial relations in the pictures.

Results. The results of the scaling task by the adult participants can be seen in Figure 2.

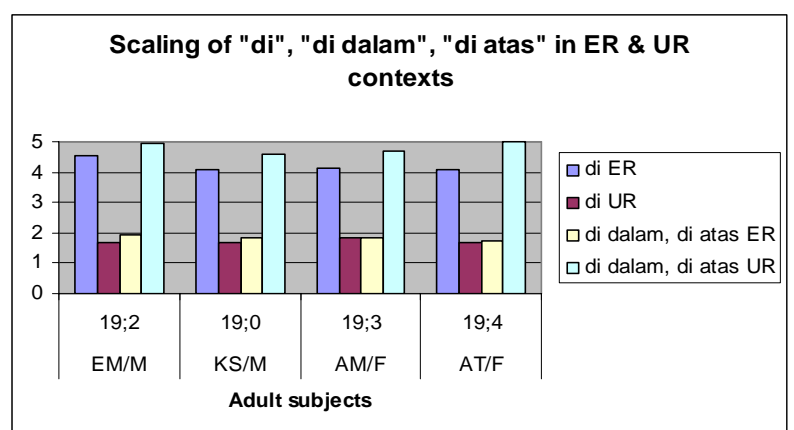

Figure 2. Scaling of di (“expect”), di atas (“expect up”), di dalam (“expect inside”) by the adult participants in ER (expected relation) and UR (unexpected relation) contexts.

Figure 2 shows that the expected preposition di ("expect") is scaled higher in the ER (expected relation) contexts than in the UR (unexpected relation) contexts. The difference is significant $(\mathrm{t}(6)=21.30, p>0.05)$. The scaling of the unexpected prepositions di atas/di dalam ("expect up/inside”), on the other hand, is higher in the 
UR contexts than that in the ER contexts. The difference is also significant (t (6) $=27.51, p>0.05)$. Therefore, the results show that the expected preposition di ("expect") is used in ER contexts, while the unexpected prepositions di atas/di dalam ("expect up/inside”) are used in UR contexts.

\section{Production Tasks}

Participants. Eighteen children participated in this experiment (3.0-11.0 years old). Eight of them (3.0-5.0) are recruited from Rama Childcare in Denpasar Bali, while the rest (5.1-11.0) are from families who used to leave their children in that childcare and families who voluntarily participated.

Regarding the subjects' socio-economic background, they are from middle to upper-middle class families based on parental education and occupational prestige. The childcare is one of the primary children's centers in Denpasar where the parents usually work in the management of private or foreign companies in Bali. This information was obtained from the application forms the parents filled in when they enrolled their children.

In addition, they are normally developing children. The information is from caregivers about their language skills, from the parents that they do not have problems of language skills in their families, and from the author's direct observation, e.g., personal talk with each child. For example, in the author's talk with them, the author showed them an Indonesian cartoon figure that they are familiar with. The author then had them answer questions about the figure such as his name, his school, his favorite food, etc.. In this fashion, the author was able to test their abilities to produce simple sentences, i.e., sentences that at least have a SVO (Subject Verb Object) word order.

To recruit the participants, written consent forms, i.e., the study proposal, containing the general idea and the detailed procedure of the study were sent to the childcare's directress and the parents. The author was assisted by one caregiver to distribute the proposal to the parents. The meeting between the experimenter, the parents, the caregivers, and the childcare's directress was conducted to provide chances for them to ask further questions about the study. For parents who could not attend the meeting, they were contacted via telephone to allow them to ask questions regarding this study. After the permission from the childcare was obtained and when the parents agreed that their children participate in this study, the parents signed the form.

Stimuli. The stimuli consist of located and reference objects that the participants are familiar with, e.g., $a$ cellphone, a glass, water, etc.. The complete list of stimuli can be seen in Table 1.

Table 1

Stimuli for the Production Tasks

\begin{tabular}{|c|c|c|c|}
\hline Containment & ERs & URs & Spatial domains \\
\hline glass & water in the glass & a cellphone in the glass & artifacts \\
\hline book & a paper in the book & a comb in the book & artifacts \\
\hline wallet & money in the wallet & a pencil in the wallet & artifacts \\
\hline \multicolumn{4}{|l|}{ Support } \\
\hline saucer & a cup on the saucer & a doll on the saucer & artifacts \\
\hline wrist & a watch on his hand & a watch on top of his hand & artifacts \\
\hline table & a glass on the table & a child bicycle on the table & artifacts \\
\hline \multicolumn{4}{|l|}{ Attachment } \\
\hline finger & a ring on his finger & a ring on top of his finger & artifacts \\
\hline foot & foot on his shoes & foot on top of his shoes & artifacts \\
\hline ear & an earring on her ear & an earring on top of her ear & artifacts \\
\hline
\end{tabular}


The objects were arranged in such a way that they showed particular kinds of spatial relations, i.e., expected and URs, that the subjects had to describe, e.g., water in the glass, an earring on an ear for the ERs; a ring on top of a finger, a comb in a book for the URs, etc.. The criteria the author used to decide the expected and unexpected relations are based upon the presence of the ERs. Thus, there is an ER between a watch and a hand when the two objects are in normal relation, while the ER is absent when the watch is put on top of a hand.

Three basic concepts of spatial relations, e.g., containment, support, and attachment, were represented in the stimuli. There were nine topological situations for each kind of spatial relations, i.e., three of them show the relations of containment, three show the support relations, and the other three show the attachment relations. Thus, a total of 18 color photographs expressing the expected and unexpected relations were used in this study. For further discussion on the stimuli, please look at Aryawibawa (2010).

Procedure. The experimenter and child participants sat at the same table. The experimenter took a located object, e.g., a cup, and asked the participant to name it. Then, the experimenter pointed to a reference object, e.g., a table, and asked the participant to name it as well. The named located object was put on the horizontal surface of the reference object. The experimenter then asked: Dimana cangkirnya? ("Where is the cup?"). The subjects provided a spatial relation between the objects, e.g., Cangkir itu di meja ("The cup is on the table”). To elicit natural knowledge of spatial relations from the participants, the experiment was conducted in play contexts. The order of the objects' relations presented to participants used a Latin square design, e.g., ERs followed with URs; URs followed with ERs. Additionally, before the actual experiment was administered, warm up sessions (three trials which are not included in the stimuli) were given to each subject to assure that the tasks worked. The entire experiment lasted for about 30 minutes for each subject.

When the stimuli were tested with the young subjects, two general patterns were observed as shown in Figures 3, 4, and 5. Please note that in this test two of the young participants at 3.10 and 3.11 were excluded from data analysis since they made more than one error, i.e., three errors of three trial items during the warm up sessions. Instead of using di, di dalam, or di atas they used the word sini "here”, not demonstratives ini "this" or itu "that", to describe the spatial situation. The use of here perhaps is the early strategy used by younger children to describe the spatial relation between objects.

Results. Figures 3-5 provide the results from the production tasks by the young subjects.

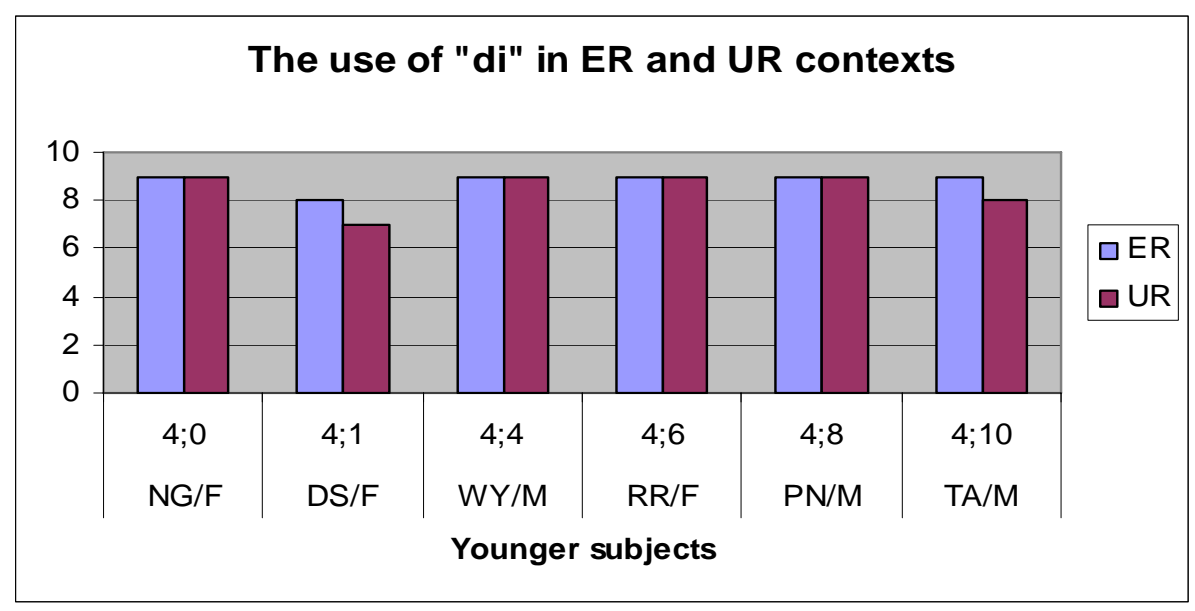

Figure 3. The use of $d i$ “expect” by the younger participants in ER and UR contexts. 


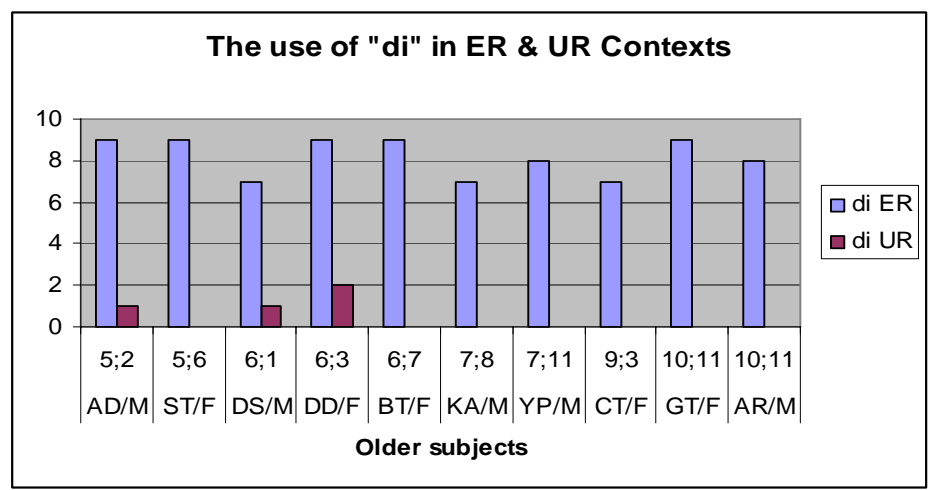

Figure 4. The use of di “expect” by the older participants in ER and UR contexts.

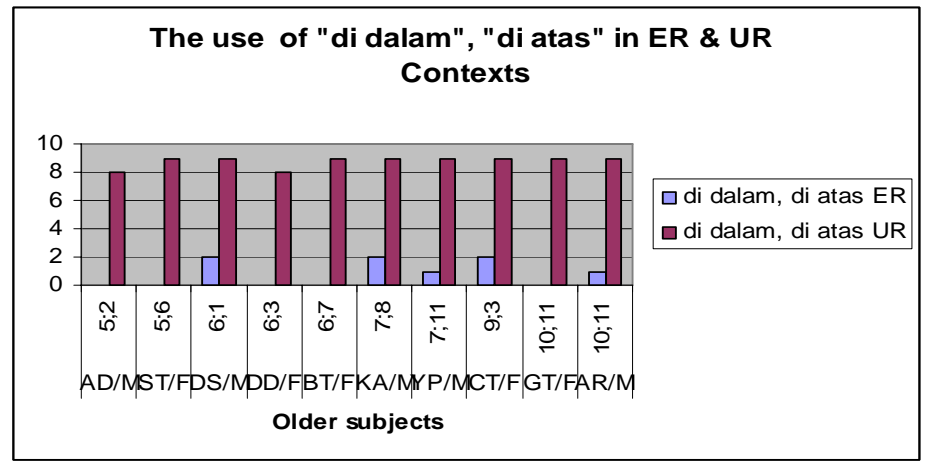

Figure 5. The use of di dalam "expect inside” and di atas “expect up” by the older participants in ER and UR contexts.

Figure 3 shows that the younger subjects (4.0-5.0) are insensitive to the difference between the expected and unexpected prepositions. As Figure 3 shows, the expected preposition di ("expect") is used in ER and UR contexts by all the subjects. There is an insignificant difference of using the expected and unexpected prepositions in ER and UR contexts (t $(6)=0.87, p<0.05)$.

For the older participants (5.1-11.0), the pattern is different from that of the younger participants. Figure 4 shows that the use of the expected preposition di ("expect") is significantly higher in the ER contexts than in the UR contexts ( $\mathrm{t}(18)=21.36, p>0.05$ ), while the use of the unexpected prepositions di atas/di dalam ("expect up/inside”) is also significantly higher in the UR contexts than in the ER contexts ( $(18)=25.02, p>0.05)$ as shown in Figure 5. These results again confirm that the expected preposition di is used in the ER contexts, while di atas/di dalam are used in the UR contexts. Based on the current findings, children seem to produce adult-like responses around five years old.

\section{Comprehension Tasks}

Participants. The same young participants (4.0-11.0) involved in the production experiment again participated in this study.

Stimuli. Since in this study the objective is to test the young participants' knowledge of spatial prepositions, i.e., to test their knowledge of locating a located object in relation to a reference object in ER and UR contexts, the stimuli employed in the previous study were again used except one objects' arrangement, i.e., a picture on a book, was excluded because of the nature of relations between the two objects. In that particular relation, it is difficult to ask the participants to put the picture in relation to the book since the picture is already a part of the book. 
Procedure. This experiment was conducted one month after the production test. The reason is that the author considers one month is sufficient for the children to forget the production tasks they did previously.

In this experiment, act-out tasks were used. The experimenter and the young participant sat at a same table. The objects were put randomly on a separate table close to the table. As in the production test, the experimenter took a located object, e.g., a watch, and put it on the table. The experimenter asked the participants to name it, e.g., Apa ini? (“What is this thing?”). They were also asked to name a reference object, e.g., his or her hand. Unlike the procedure in the production test, the experimenter now asked the participant to put the watch on his or her hand, e.g., Coba taruh jamnya di tangannya! (“Put the watch on your hand, please!”).

What the author manipulated in this experiment was that the author used the verb taruh ("put") followed with $d i$ ("expect”) or di atas/di dalam ("expect up/inside”), not the verb pakai ("wear") followed with di ("expect”) or di atas/di dalam ("expect up/up") in the author's instructions. The verb taruh ("put”) in Indonesian does not entail that someone has to wear something. If, for example, the author used the verb pakai ("wear") in the author's instruction, e.g., pakai jamnya di tangan ("put the watch on your hand"), the subjects must know how to wear it as people normally do. Thus, by using the verb taruh ("put"), the author thought he could test the importance of the ER between the watch and the hand. If they put the watch on their hands as it normally happens, this indicates that the ER is crucial in Indonesian. But, if, for example, the watch is put on top of hand, i.e., not in a position as how the watch is normally worn, which is more appropriate as a response of di atas, to respond to the use of $d i$ in the author's instruction the results should be reevaluated.

The order of spatial relations asked to the participants followed the Latin square design used in the production experiment. As in the previous experiment, three trials, which were not included in the stimuli, were given to the participants before the actual experiment. If ER contexts are responded with di, e.g., the ring is put on a finger in a normal relation as a response to the author's instruction taruh cincinya di jarimu ("put the ring on your finger"), the author scored it 1 . And if UR contexts are responded with di dalam or di atas, e.g., the watch is put on top of a hand as a response to the author's instruction taruh jamnya di atas tanganmu ("put the watch on top of your hand"), the author scored it 2. The experiment lasted for about 30 minutes for each subject.

Results. Figures 6-7 show the results of participants' knowledge of using the expected and unexpected prepositions in the ER and UR contexts.

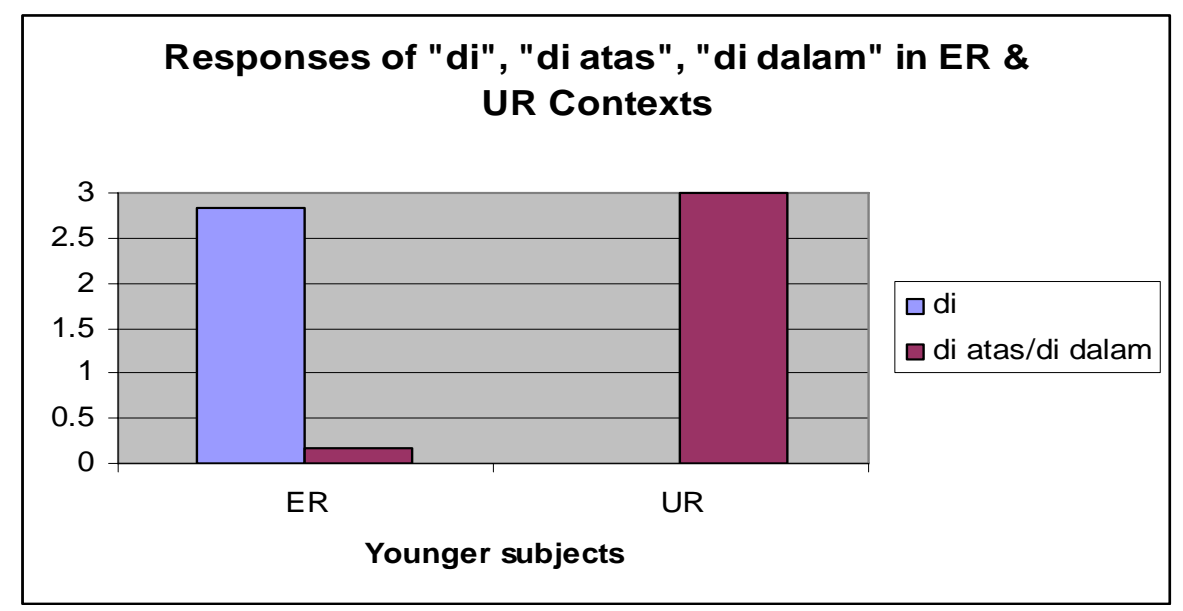

Figure 6. The comprehension of $d i$ “expect” in ER and UR contexts by the younger subjects. 


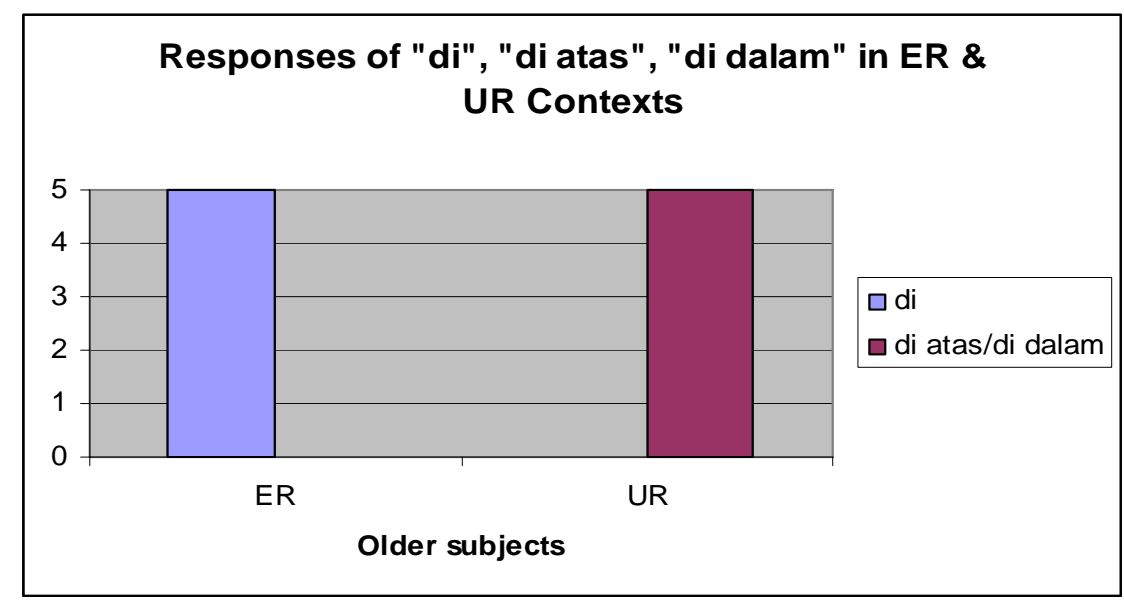

Figure 7. The comprehension of di atas/ di dalam “expect up/in” in ER and UR contexts by the older subjects.

Unlike the results shown by the younger participants in the production tasks, i.e., the younger subjects overgeneralized the expected preposition di ("expect"), the results in the comprehension test show that they do have knowledge of the expected preposition $d i$ and the unexpected prepositions di dalam or di atas. More specifically, their performance based on the author's instruction using the expected preposition di "expect" is higher in the ER contexts than in the UR contexts, e.g., the ring is put on a finger as it is normally worn, the money is put in a wallet in a normal relation, as shown in Figure 6. Their performance based on the author's instruction using the unexpected prepositions di dalam or di atas is higher in the UR contexts than in the ER contexts, e.g., the watch is put on top of a hand in an atypical relation, the earring is put on top of her ear.

The same pattern is also observed in the older subjects' results. Their performance based on the author's instruction using the expected preposition di ("expect”) is significantly higher in the ER contexts than in the UR contexts, i.e., none of the older subjects used $d i$ in the UR contexts, as indicated in Figure 7. And their performance based on the author's instruction using the unexpected prepositions is significantly higher in the UR contexts than in the ER contexts, i.e., none of the older subjects used di atas or di dalam in the ER contexts. These results suggest that both the younger and older subjects do have the knowledge of the expected and unexpected prepositions. But, why did the younger subjects not produce the unexpected prepositions in their production task? The author will try to answer this question in the discussion section.

\section{Discussion}

The findings of current study, in addition to those by Carlson-Radvansky et al. (1999), once again provide further evidence that functions, i.e., the expected functions of artifacts, play crucial roles in the use of spatial terms. As can be seen from the results, especially the use of spatial terms by the older participants (5.1-11.0) in the production tasks, the presence of the expected function of objects influences their use of spatial terms in Indonesian. More specifically, when the ER is present, the expected preposition di ("expect") is used to describe the spatial relations between objects, e.g., a picture in a book, water in the glass, money in the wallet, a watch on wrist, a ring on a finger, etc.. On the other hand, when the ER is absent, e.g., a cellphone in a glass, a comb in a book, a doll on a saucer, etc., the unexpected prepositions di dalam ("expect inside”) or di atas ("expect up") are used. Thus, the facts are further evidence that the ER is important in Indonesian. 
Another important point that can be observed from the current findings is that the objects' function is not only restricted to the designed functions of objects, i.e., a bowl functions to contain, a table functions to support, as indicated in Carlson-Radvansky's study, but also to the functions that are typically connected to the objects, i.e., if the located objects are typically related to the reference objects such as a watch on hand, earring on ear, money in the wallet, etc.

What is another important lesson that we can learn from these findings? To answer this question, let us look at what Bowerman and Choi (2001, pp. 490-491) found in their study of acquisition of topological relations in English, Korean, and Dutch. They pointed out that English children consistently distinguished containment from support, e.g., put in, put on, from an early age, while Korean children were more attentive to the distinction between the interlocking relations ( $k$ kita) and various "looser" kinds of joinings including putting clothing onto different body parts from an early age. The author's study, however, shows a different pattern. The children especially the younger subjects in their production tasks acquire the expected prepositions earlier than the unexpected prepositions. Thus, it seems that the learnability factor plays a crucial role in the acquisition of the expected and unexpected prepositions in Indonesian. Put another way, for children to discover the target grammar, i.e., the expected and unexpected prepositions, they go through exposure to sentences of their parents or of their linguistic communities. The question now is: How to account for the learning process by children? The story below as suggested by Bowerman and Choi (2001, p. 497) may explain the learning process.

Children construct spatial semantic categories over time on the basis of the way they hear words used in the input, and in doing so, they draw on perceptual sensitivities and conceptual biases they bring with them to the task. Language input helps the learner decide which kind of similarities and differences among referent situations are important for purposes of selecting a word, but the sensitivities to these properties must of course ultimately be supplied by the child. Some properties are undoubtedly more accessible or salient to learners than others, and categories that depend on these will, all else being equal, be learned earlier and with fewer errors than categories that depend on properties that are cognitively or perceptually more obscure. Where the relevant properties are not obvious, because they are either low in salience or maturationally not yet available, children will make errors, either underextending or overextending words according to principles that are more readily available to them.

What specific factors affect the acquisition of the expected and unexpected prepositions in Indonesian? It appears that it is connected to children's conceptual and linguistic development. In other words, for children to use the unexpected prepositions appropriately their conceptual and linguistic knowledge has to be "mature" which generally correlates with their age. What the author means by "mature" here is in the sense of Borer and Wexler's Maturation Hypothesis (1987, pp. 123-130), in which the maturation is biologically determined. The evidence for this argument can be seen in Figure 3 that even though the younger subjects (4.0-5.0) have the knowledge of expected and unexpected prepositions (from the comprehension tasks) they still cannot produce the two prepositions appropriately. The explanation for this fact seems to be related to the fact that their production ability has not yet become mature. On the other hand, the older subjects (5.1-11.0), like the adults, can produce the two prepositions accurately as Figures 4-5 show. It is, the author argues based on the results, because they have already had matured conceptual and linguistic knowledge.

The same line of argument to support my argument can be pointed out from Bowerman and Choi (2001, pp. 491-497) conducting comprehension tests, i.e., non-verbal tasks, for young children between 18 and 23 months 
(20 learning English and 10 learning Korean). At this age, according to the parents, only six of English children and two of Korean children produced the target words for their languages.

Bowerman used a preferential-looking paradigm. The stimuli consisted of four videotaped actions to test if the children in each language understand the properties of events relevant to the two target words, i.e., containment for (put) in in English and tight fit or interlocking for kkita in Korean. In the first and third pair of stimuli, the matching scene was the same for the two languages. In the first pair, the peg is put in a block with holes into which the peg is put, and on a solid block. In the third pair, the book is put in a cover box, and on another book. For the contexts, where the peg is put in the holes of the block and the book is put in the cover, both (put) in and kkita were qualified in English and Korean. In the second and fourth pairs of stimuli, the containment and tight fit were split. In the second pair, a lego was put in a large plastic box in which (put) in matches for English, and a lego was put in another lego in which kkita is appropriate in Korean. In the fourth pair, a ring was put in a basket in which (put) in was expected in English, and a ring was tightly put on a pole in which kkita matches in Korean.

The child sat on parent's lap facing two TV monitors mounted each other. A loudspeaker is placed between the two monitors through which the children could hear auditory input. If the English children understand the properties of in, they should look longer at scenes showing containment regardless of tightness. And if the Korean children understand kkita they should look longer at scenes showing tight-fitting relation regardless of whether the fit involves containment or surface attachment. The results showed that at the age between 18 and 23 months the English and Korean children understand in and kkita respectively (though the majority of the children in the two languages could not produce the target words). Thus, for English and Korean children to be able to produce the target words, they should have mature conceptual and linguistic knowledge, which starts around two years old according to the subjects involved in Bowerman's production elicitation test.

The other evidence supporting this argument is from the results shown in Figures 6-7 that only three of the older subjects (with initials KA, CT, and GT) show their hesitation to perform the use of expected and unexpected prepositions. For examples, when the author asked them to put the earring on top of their ears they asked the author back di atas telinga apa di telinga (“is it on top of ear or on ear?”). This fact could possibly imply that the three subjects' conceptual and linguistic knowledge have reached more advanced maturation than the other seven subjects in those Figures.

The argument that the patterns of the young subjects' use of the spatial prepositions are related to the conceptual and linguistic development is in agreement with what Johnston and Slobin (1979) argued that when children cognitive capacity develops as their ages increase their understanding of more complex concepts also develops. Moreover, Johnston and Slobin (1979, pp. 531-532) explained that there are four linguistic factors that could delay the acquisition of prepositions. They are lexical diversity, e.g., next to, beside, by, close to in English while only one form in Turkish, yaninda, clear etymology, e.g., in back, in front in contrast with between, morphological complexity, e.g., on top of, in the middle of, and homonymity, e.g., back and front are homonyms in the sense that they are used to encode featured and non-featured objects. Johnston and Slobin (1979, p. 532) further explain that children on the ground prefer one-to-one mappings between semantic concepts and surface forms. Thus, regarding the current study, the delay of the acquisition of unexpected prepositions in Indonesian by the younger subjects is apparently due to their immature linguistic knowledge, i.e., due to the morphological complexity of such prepositions, e.g., di dalam, di atas. 
Given the importance of the ER in Indonesian, the author predicts that the stages of the acquisition of topological prepositions in Indonesian are as follows: Expected preposition (di ("expect")) < Unexpected prepositions (di dalam (“expect inside”), di atas (“expect up”)).

The findings of the current study also lend further support to Feist’s (2008, p. 117) argument that language acquisition, i.e., preposition acquisition by children, is through an evolution. But note again that what Feist defines as function is in the sense of "designed" function defined by Vandeloise and Piaget, i.e., the functions of a reference object to contain or support a located object. In her study, Feist involved 16 preschooled-aged children (mean age 56.5 months) and eight 13-year-old children (mean age 161 months). The stimuli used by Feist were 12 pictures depicting two Grounds, i.e., an ambiguous dishlike tray and a hand, paired with two Figures, i.e., a firefly and a coin, at three levels of concavity.

The stimuli were randomized and presented individually on a computer screen, interspersed with four catch trials and preceded by two training trials. When the picture was present on the screen the participant was asked if the Figure in or on the Ground.

The results showed that the influence of function varied according to the subjects' age. For the 13-year-old group, like adults in their earlier study, their use of in and on according to the labeling conditions, i.e., in the bowl condition and in the plate condition, was only there when responding to pictures depicting inanimate Ground. For the preschoolers, however, their across-the-board increase in the use of in in the bowl condition relative to the plate condition was observed. In short, Feist explains that when the subjects' conceptual and linguistic knowledge are mature, the acquisition of more complex concepts and more complex linguistics forms occur.

In relation to the current study, in the beginning children appear to acquire a very basic concept, i.e., ER. When their conceptual and linguistic knowledge get matured, they acquire the UR.

\section{Conclusions}

The results of current study suggest that the expectedness of spatial relation between objects do affect the acquisition of topological preposition in Indonesian. When the ER is there in the spatial relation between objects the expected preposition di "expect" is used to describe such a context. But, the unexpected prepositions di dalam "expect inside”, di atas "expect up" are used when the ER is absent.

The conceptual and linguistic concepts seem to influence the acquisition of both expected and unexpected prepositions in Indonesian. More specifically, to be able to produce the two prepositions children should have matured conceptual and linguistic knowledge. The delay of the acquisition of the unexpected prepositions in Indonesian may also be specifically caused by the complexity of syntactical forms of such prepositions, i.e., $d i$ dalam ("expect inside"), di atas ("expect up"), which are more complex than the expected preposition, i.e., di (“expect”).

The findings of the current study brings some implications to the claims of both the strong universal conceptual categories or UCC, e.g., Johnston and Slobin (1979), Herskovits (1982, 1986), and the universal tendencies or UT, e.g., Levinson et al. (2003), on the basic concepts relevant to the use of spatial prepositions. According to the UCC, the concept containment and support are basic in the use of spatial terms in English. But, the UT claims that these concepts are not confirmed in the nine unrelated languages studied by Levinson et al.. In fact, they found that the concept attachment (also superadjacency, full containment, and subadjacency) is 
important in those languages. This study, however, reveals that those concepts, e.g., containment, support, attachment, are not relevant in Indonesian.

This study, however, is still preliminary. The stimuli, e.g., the comprehension tasks, need further evaluation. So far, what the author manipulated was that the use of the verb taruh ("put”), which does not imply that somebody has to wear something in Indonesian, followed with di to test the prominence of the ER. In future investigation, for example, the author should look at the subjects' responses when the author asks them to put various located objects relative to a reference object, e.g., a pencil or a rubber in a pencil box and key or money in a pencil box, etc., using both the expected preposition di and unexpected preposition di dalam in turn.

\section{References}

Aryawibawa, I. N. (2008). Semantictypology: Semantics of locative relations in Rongga (M.A. thesis, Kansas University).

Aryawibawa, I. N. (2010). Spatial reference in Rongga, Balinese, and Indonesian (Ph.D. thesis, Kansas University).

Borer, H., \& Wexler, K. (1987). The maturation of syntax. In T. Roeper \& E. Williams (Eds.), Parameter setting (pp. 123-172). Boston: D Reidel Publishing Company.

Bowerman, M., \& Choi, S. (2001). Shaping meanings for language: Universal and language-specific in the acquisition of spatial semantic categories. In M. Bowerman \& S. C. Levinson (Eds.), Language acquisition and conceptual development. Cambridge: Cambridge University Press.

Carlson-Radvansky, L. A., Covey, E. S., \& Lattanzi, K. M. (1999). "What” effects on “where”: Functional influences on spatial relations. Psychological Science, 10(6).

Dromi, E. (1979). More on the acquisition of locative prepositions: An analysis of Hebrew data. Child Language Journal, 6, 547-561.

Feist, M. I. (2008). Changing shape of prepositional meanings. In H. Chan, H. Jacob, \& E. Kapia (Eds.), Proceedings of the 32nd science, annual Boston University coverence on language development (Vol. 1, pp. 108-119). Somerville: Cascadilla Press.

Herskovits, A. (1982). Space and the prepositions in English: Regularities and irregularities in a complex domain. Ann Arbor Michigan: University Microfilms International.

Herskovits, A. (1986). Language and spatial cognition. Cambridge: Cambridge University Press.

Johnston, J. R. (1985). Cognitive prerequisite: The evidence from children learning English. In D. I. Slobin (Ed.), The crosslinguistic study of language acquisition (Volume 2): Theoretical issues (pp. 961-997). New Jersey: Lawrence Erlbaum Associates, Inc., Publishers.

Johnston, J. R., \& Slobin, D. I. (1979). The development of locative expressions in English, Italian, Serbo-Croatian and Turkish. Child Language Journal, 6, 529-545.

Levinson, S., Meira, S., \& The Language and Cognition Group. (2003). “Natural concepts” in the spatial topological topological domain-Adpositional meanings in crosslinguistic perspective: An exercise in semantic typology. Language, 79, 485-516.

Vandeloise, C. (1991). Spatial prepositions: A case study of French. Chicago: The University of Chicago Press. 